\section{Doi: $10.15863 / \mathrm{TAS}$ \\ International Scientific Journal Theoretical \& Applied Science}

p-ISSN: 2308-4944 (print)

e-ISSN: 2409-0085 (online)

Year: $2015 \quad$ Issue: 02 Volume: 22

Published: 28.02.2015 http://www.T-Science.org
Eugeniya Aleksandrovna Danchenko graduate student of the department Banking Rostov State University of Economics, Russia DEAr_910@mail.ru

SECTION 31. Economic research, finance,

innovation, and risk management.

\title{
FEASIBILITY STUDY BAN PERCENT IN THE ISLAMIC FINANCIAL SYSTEM
}

\begin{abstract}
The main difference between Islamic banking is the prohibition of the surplus, which is defined as any unjustified capital gains when the loan or when the bargain. Most Islamic scholars refers to the concept of "surplus" is not only high, usurious, but any interest on loans. Interest of bankers to innovative traditional banks financial products is due not only need to attract customers with moral principles, negatively related to speculative transactions, but also the fact that Islamic financial institutions significantly affected by the impact of the global financial crisis of 2007-2009. The aim of the study is to explore the concept of "interest" in the Islamic banking system and the role of interest in the sustainable functioning of Islamic banks in the global financial markets during the crisis. To achieve this goal have been resolved following tasks: formulated the basic concept of "interest"; an analysis of the credit process in Islamic and conventional banking systems; to analyze the effect of interest on the functioning of the economy. Methodology. Based on the analysis of traffic patterns of cash in the traditional and Islamic banking systems identified the main factors of influence on the economy. The Results. Analysis of the Islamic finance model showed projects focus on the growth of production and improve the welfare of the population through interest-free financing trade. This orientation of Islamic banking products is a factor of stability of the banking system and the economy as a whole. It is concluded that the use of interest in the economy leads, firstly, to an unreasonable increase in the money supply, which in turn provokes a rise in inflation, and secondly, to increase the interest burden on the consumers of the goods, thereby reducing their consumption, third contributes to stagnation of production.
\end{abstract}

Key words: money, interest, Islamic finance, the excess inflation.

Language: Russian

Citation: Danchenko EA (2015) FEASIBILITY STUDY BAN PERCENT IN THE ISLAMIC FINANCIAL SYSTEM. ISJ Theoretical \& Applied Science 02 (22): 21-24. doi: http://dx.doi.org/10.15863/TAS.2015.02.22.5

\section{ЭКОНОМИЧЕСКОЕ ОБОСНОВАНИЕ ЗАПРЕТА ПРОЦЕНТА В ИСЛАМСКОЙ ФИНАНСОВОЙ СИСТЕМЕ}

Аннотация: Главным отличием исламской банковской системы является запрет на излишек, под которым понимается любое неоправданное приращение капитала при займе или при осуществлении торговой сделки. Больиинство исламских ученых относит к понятию «излишек» не только высокий, ростовщический, но и любой ссудный процент. Интерес банкиров к инновационным для традиционных банков финансовым продуктам обусловлен не только потребностью привлечения клиентов с моральными приниипами (негативно относящихся к спекулятивным операциям), но и тем, что исламские финансовые институты незначительно пострадали от воздействия глобального финансового кризиса 2007-2009 г2. Целью исследования является изучения понятия «прочента» в исламской банковской системе и роль процента в устойчивом функционировании исламских банков на мировом финансовом рынке в период кризиса. Для достижения поставленной иели были решены следуюшие задачи: сформулированы основные понятия «процента»; проведен анализ кредитного процесса в исламской и традиционной банковской системах; проведен анализ влияния процента на функиионирование экономики. Методология. На основе анализа схем движения денежных средств в традиционной и исламской банковской системах выявлены основные факторы влияния на экономику. Результаты. Анализ процесса финансирования исламской модели 
показал ориентированность проектов на рост производства и улучшению благосостояния населения путем беспроиентного финансирования товарооборота. Данная направленность исламских банковских продуктов является одним из факторов устойчивости банковской системы и экономики в целом. Сделан вывод о том, что использование прочента в экономике приводит, во-первых, к необоснованному росту денежной массы, что в свою очередь провоцирует рост инфляции, во-вторых, увеличению процентного бремени на потребителей товаров, сокращая тем самым их потребление, в- третьих, способствует стагнации производства.

Ключевые слова: деньги, процент, исламские финансы, излишек, инфляциия.

Главной особенностью исламских финансов является отказ от ссудного процента. Вознаграждение собственнику капитала не должно принимать форму выплаты заранее установленной суммы, гарантированной вне зависимости от доходности предприятия, как это происходит в случае взимания процента. Согласно нормам исламского права, праведно лишь то богатство, источником которого являются собственный труд и предпринимательские усилия его владельца, а также наследство или дар. Любое неоправданное приращение капитала при займе или при осуществлении торговой сделки является запретным.

Деньги в исламской экономической теории всегда определялись как всеобщий эквивалент стоимости товаров и активно использовались в международной торговле, которая была очень развита со времен Вавилона и Месопотамии. На основании этого процент воспринимается в исламе как приращение за счет спекуляций, именно поэтому ислам категорически запрещает получать процентную надбавку за одолженную сумму. Если кредитор во время дачи в долг ставит условие, что при возврате должник обязан вернуть больше, чем он брал, то это считается процентной надбавкой и является запрещенной. [2]

Таким образом, схема финансового посредничества в исламской финансовой системе в классическом виде выглядит так: предприятие производитель ликвидирует нехватку денежных средств (L) на производство товара/услуг путем заимствований у финансового посредника и продает товар по цене (L'). (Рисунок 1) Для приобретения товара/услуги потребитель имеет возможность занять средства у финансового посредника. (L') Главным недостатком данной схемы является отсутствие дохода финансового посредника. Однако беспроцентная схема финансирования товарообмена имеет ряд преимуществ для субъектов-участников. Вопервых, финансовый посредник стимулирует потребление товаров/услуг и развитие производства товаров/услуг, что является важным показателем развития экономики региона в целом.

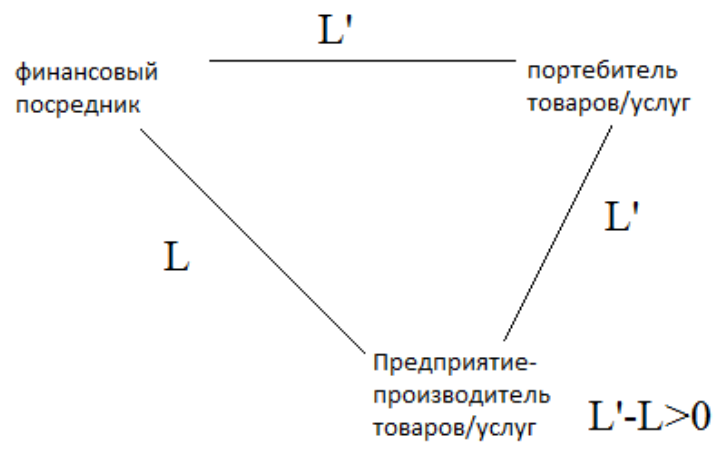

Рисунок 1 - Схема движения капитала в исламской финансовой системе.

где L - затраты на труд и материаль, необходимые для производства товара/услуги;

L' - цена реализации товара/услуги, устанавливаемая производителем товара.

Источник: составлено автором

Во-вторых, предприятие за счет разницы затрат на производство товаров/услуг и доходом от реализации товаров/услуг (L'-L>0) имеет возможность расширять производство, улучшать качество товаров/услуг, повышать благосостояние работников, формировать инвестиционные фонды на счетах финансового посредника. В-третьих, сохраняется баланс денежной массы в экономике, что обеспечивает приемлемый инфляционный фон.

\section{ISPC European Technology in Science,}

Malmö, Sweden 
При начислении простых и сложных процентов финансовые посредники используют формулы (1) и (2) соответственно.

$$
\begin{gathered}
\mathrm{FV}=\mathrm{P}+\mathrm{P} * \mathrm{n} *(\mathrm{~L}+\mathrm{K})(1) \\
\mathrm{FV}=\mathrm{P} *(1+\mathrm{L}+\mathrm{K})^{\mathrm{n}}(2)
\end{gathered}
$$

Если рассматривать финансирование производства/покупки товара с использованием процентов, можно получить следующую схему. (Рисунок 2) Денежные средства, выдаваемые финансовым посредником в долг, являются на банковском рынке товаром и обозначаются $\mathrm{P}$ товар, выраженный в деньгах. За пользование денежными средствами финансовый посредник взимает проценты (i), которые включают в себя расходы банка на оплату труда, материалы $(\mathrm{L}-\mathrm{B}$ долях от общей суммы долга) и плату за использование заемных средств (К - в долях от общей суммы долга). Через $\mathrm{n}$ времени пользователь средств возвращает финансовому посреднику основную сумму долга (Р) и начисленные на нее проценты $\mathrm{P} * \mathrm{i}$, что в финансовой математике принято обозначать FV будущая стоимость.

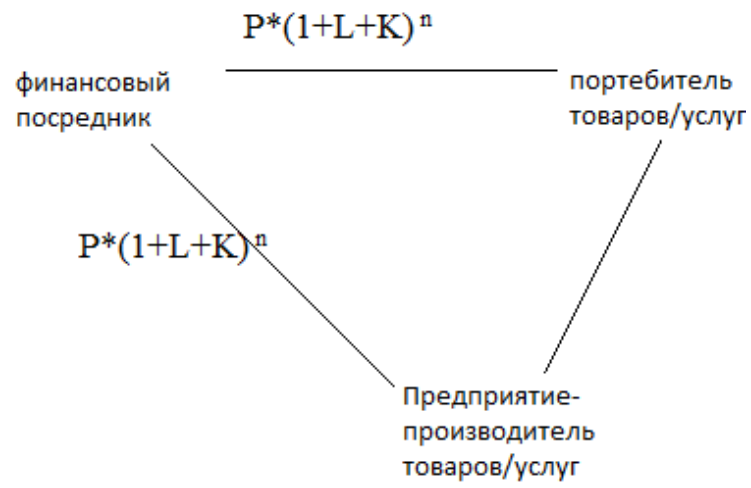

\section{Рисунок 2 - Схема движения капитала при финансировании производства/покупки товара с использованием процентов.}

Рассмотрим приращение денежной массы при $\mathrm{n}=2$ :

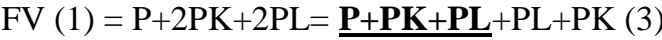

$\mathrm{FV}(2)=\underline{\mathbf{P}+\mathbf{P K}+\mathbf{P L}}+\mathrm{PL}+\mathrm{PK}+2 \mathrm{KL}+\mathrm{PL}^{2}+\mathrm{PK}^{2}$,

где $\underline{\mathbf{P + P K}+\mathbf{P L}}-$ средства, необходимые банку для безубыточной деятельности;

$(\mathrm{PL}+\mathrm{PK}),\left(\mathrm{PL}+\mathrm{PK}+2 \mathrm{KL}+\mathrm{PL}^{2}+\mathrm{PK}^{2}\right)-$ излишек - доход банка, который распределяется в резервный фонд банка, на выплату дивидендов акционерам и прочее.

В данной математической модели в основу процентной ставки включены только два показателя: плата за заемные средства и оплата труда сотрудников финансового посредника. Если включить в процентную ставку доли отчислений в резервные фонды финансового посредника (RF), арендные платежи за помещение (R) и прочее, формула (2) преобразуется в (5), что увеличивает излишек денежных средств в обращении и способствует росту инфляции.

$$
\mathrm{FV}=\mathrm{P} *(1+\mathrm{L}+\mathrm{RF}+\mathrm{R}+\ldots+\mathrm{K})^{\mathrm{n}}(5)
$$

Таким образом, при начислении сложных процентов в $\mathrm{n}=2$ образуется излишек $2 \mathrm{KL}+\mathrm{PL}^{2}+\mathrm{PK}^{2}$, который увеличивает количество денежной массы и тем самым провоцирует рост инфляции.
При реализации схемы финансирование производства/покупки товара/услуг с использованием процентов, возникает разрыв: предприятие может включить издержки за пользование средствами финансового посредника в стоимость товара/услуги, тем самым увеличив стоимость для потребителя. Потребитель при приобретении товара/услуги в кредит выплачивает проценты по своему долгу финансовому посреднику и по долгу предприятия - производителя, таким образом, потребитель несет двойное бремя перед финансовым посредником. Данная ситуация сказывается на финансовом состоянии потребителя, снижая его покупательную способность и сокращая потребление товаров/услуг.

Осуждение взимания ссудного процента в исламской модели обосновывается следующими соображениями: за счет взимания процентов денежные состояния быстро увеличиваются через регулярные промежутки времени, т.е. они имеют экспоненциальную динамику роста, что объясняет, почему в прошлом через регулярные промежутки времени возникали сложности с системой денежного обращения, почему возникают они и сейчас. Однако в исламской экономической модели предусмотрено, что владелец денежных средств может получить 
вознаграждение или часть прибыли (в зависимости от вида операции и договора) от пользователя.

Воздействие процентного механизма на денежную систему определяется его частичной завуалированностью. Большинство людей считает, что они платят проценты только тогда, когда берут деньги в кредит, и, если уплата процентов нежелательна, достаточно просто не брать деньги в кредит. Однако, это не так, потому что цена каждого товара, который мы оплачиваем, включает в себя процентную часть. Эта доля колеблется для товаров и услуг, приобретаемых нами в соответствии с величиной затраченного капитала. Этот факт превосходно объясняет сущность механизма, позволяющего богатым становиться все богаче, а бедных делающего все беднее.

Таким образом, можно сделать вывод о том, что использование процента в экономике приводит, во-первых, к необоснованному росту денежной массы, что в свою очередь провоцирует рост инфляции, во-вторых, увеличению процентного бремени на потребителей товаров, сокращая тем самым их потребление, в- третьих, способствует стагнации производства.

\section{References:}

1. Danchenko EA (2014) The spread of Islamic banking products in global financial markets «7th International Scientific Conference Science and Society». 25-26 November 2014 http://scieuro.com/articles

2. Danchenko EA (2015) Mesto protsenta v islamskoy bankovskoy sisteme // Finansovye issledovaniya - 2015. - №1 (46)

3. Danchenko EA (2011) Perspektivy vnedreniya «islamskikh okon» v bankovskuyu sistemu Rossii //Sovremennye tendentsii v ekonomike i upravlenii: novyy vzglyad. 2011. № 12-2. pp. 50-55.

4. Efremenko IN (2008) Vzaimosvyaz' razvitiya mirovoy finansovoy arkhitektury i sistemnykh finansovykh krizisov // Finansovye issledovaniya. 2008. № 20. pp. 3-12.

5. Efremenko IN (2007) Islamskie finansy v formirovanii novoy institutsional'noy osnovy mirovoy finansovoy arkhitektury. Finansovye issledovaniya. 2007. № 16. pp. 3-9. http://www.finis.rsue.ru/2007-3/efremenko.pdf

6. (2004) Islamskie finansy v sovremennom mire: ekonomicheskie i pravovye aspekty/ Pod red. R.I. Bekkina. - Moscow: Ummah, 2004.

7. Bekkin R (2007) Ssudnyy protsent v kontekste religiozno-eticheskikh

khozyaystvennykh sistem proshlogo i sovremennosti // Voprosy ekonomiki. 2007. № 2. pp. 141-157.

8. Bekkin R (2011) Opyt i perspektivy islamskoy finansovoy sistemy v Rossii // Rossiya i musul'manskiy mir. 2011. № 6. pp. 30-36.

9. Kochmola KV (2007) Islamskie finansovye instituty $\mathrm{v}$ mirovoy finansovoy arkhitektury: monografiya. - RGEU "RINKh", g. Rostov-n/D $2007-368$

10. Maznyak VM (2003) Bankovskoe delo i organizatsionnye osobennosti kommercheskogo banka // Finansovye issledovaniya. 2003. № 1 (6). pp. 25-28.

11. Selivanova TA (2011) Problemy i faktory formirovaniya protsentnoy politiki kommercheskikh bankov // V sbornike: Rynochnaya ekonomika i finansovo-kreditnye otnosheniya uchenye zapiski. Rostov-na-Donu, 2011. pp. 51-57.

12. Semenyuta OG, Shevtsova OV (2003) Transfernoe tsenoobrazovanie kak element operativnogo upravleniya protsentnoy politikoy mnogofilial'nogo banka // Finansovye issledovaniya. 2003. № 1 (6). pp. 29-34. 